Article

\title{
Surveillance and Resilience in Theory and Practice
}

\author{
Charles D. Raab ${ }^{1, *}$, Richard Jones ${ }^{2}$ and Ivan Szekely ${ }^{3}$ \\ ${ }^{1}$ School of Social and Political Science, University of Edinburgh, Edinburgh, EH8 9LD, UK; E-Mail: c.d.raab@ed.ac.uk \\ ${ }^{2}$ School of Law, University of Edinburgh, Edinburgh, EH8 9YL, UK; E-Mail: richard.jones@ed.ac.uk \\ ${ }^{3}$ Eotvos Karoly Policy Institute, 1088 Budapest, Hungary; E-Mail: szekelyi@ceu.edu \\ * Corresponding author
}

Submitted: 6 January 2015 | In Revised Form: 28 April 2015 | Accepted: 5 May 2015 |

Published: 30 September 2015

\begin{abstract}
Surveillance is often used as a tool in resilience strategies towards the threat posed by terrorist attacks and other serious crime. "Resilience" is a contested term with varying and ambiguous meaning in governmental, business and social discourses, and it is not clear how it relates to other terms that characterise processes or states of being. Resilience is often assumed to have positive connotations, but critics view it with great suspicion, regarding it as a neoliberal governmental strategy. However, we argue that surveillance, introduced in the name of greater security, may itself erode social freedoms and public goods such as privacy, paradoxically requiring societal resilience, whether precautionary or in mitigation of the harms it causes to the public goods of free societies. This article develops new models and extends existing ones to describe resilience processes unfolding over time and in anticipation of, or in reaction to, adversities of different kinds and severity, and explores resilience both on the plane of abstract analysis and in the context of societal responses to mass surveillance. The article thus focuses upon surveillance as a special field for conceptual analysis and modelling of situations, and for evaluating contemporary developments in "surveillance societies".
\end{abstract}

\section{Keywords}

democracy; privacy; public goods; resilience; security; surveillance

\section{Issue}

This article is part of the special issue "Surveillance: Critical Analysis and Current Challenges", edited by James Schwoch (Northwestern University, USA), John Laprise (Independent Researcher) and Ivory Mills (Northwestern University, USA).

(C) 2015 by the authors; licensee Cogitatio (Lisbon, Portugal). This article is licensed under a Creative Commons Attribution 4.0 International License (CC BY).

\section{Introduction}

The dramatic revelations made in 2013 by Edward Snowden concerned the extensive and intensive surveillance operations of USA and allied intelligence services, involving covert collection of communications data on a massive scale, with or without clear legal warrant and often with the complicity of private communications, computing and media companies (Greenwald, 2014). Many of the specific and previously top-secret mass surveillance programmes that Snowden revealed were shown to be operating on an unimaginably huge scale. Increasing public knowledge of these practices has stimulated a variety of responses from citizens, governments, civil society organisations, and other interests. Their views include a search for types of response that include opposition, a plea for regulation and control, and better ways of shaping the relationship between national security and the requirements of liberal democracy. Reactions by privacy and Internet activists and advocates, by some parts of the media, and by a few politicians and lawyers, have been among the most considered, forceful and promising, with proposed reforming measures ranging from the technical to the legal, regulatory and political. However, we do not yet possess the conceptual apparatus to model the relationship these disparate means of addressing surveillance have to one another, nor to 
their collective efficacy in the face of the threats posed by mass surveillance programmes. ${ }^{1}$

Although mass surveillance started well before $9 / 11$, its rapid expansion since then is often understood as a reaction to the terrorist attacks. Indeed, many countries have expanded their counter-terror activities over the same time period, and the term "resilience" is often found in official discourses of counterterror strategies, as well as serving as an analytical term in security studies and other policy areas. It also features in popular but vague inspirational language that is meant to connote an attitude, or stance, to be taken in a wide variety of adverse circumstances. The use of this term (along with the related term, "resilient") has noticeably proliferated in recent years, applied to a vast array of systems, contexts, processes and policies. White and O'Hare (2014), for example, found that some 800 official UK policy documents published since 2005 contained versions of the term, including in the area of counter-terrorism. The properties of resilience are considered by policy-makers generally to be beneficial, and the aim of making human and natural systems resilient taken to be worthy of approval as well as deserving of the allocation of resources. Evaluations of individual, group, societal and system performance in terms of their resilience have become commonplace, and criticism of non-resilience has become justified in the name of improvement. Few would wish to be labelled with various possible antonyms: brittle, fragile, inflexible, unbending. In sum, the art, craft and science of making people and things resilient all flourish in the face of threats that may or may not be known or predicted.

Amidst this proliferation, framing theory and policy in terms of "resilience" has attracted its critics as well as engendered debate. Chandler established the journal Resilience "to critically engage with the world around us, to ask new questions of it" (Chandler, 2013a). The study of resilience is seen as multidimensional, ambitiously embracing practices, policies, discourses, processes, spaces of construction, economics, politics, and subjectivities. The concept "resilience" is used almost magnetically to re-orientate the particles of diverse fields, disciplines, approaches and substantive research around a new way to frame and comprehend their complementarity. Against this initiative, Neocleous has attacked "resilience" as a project for "colonizing the imagination" and making the state and capitalism more resilient. It represents an uncritical diversion from the need for resistance that follows the

\footnotetext{
1 This article emerges from the IRISS (Increasing Resilience in Surveillance Societies) Project (EC Grant Agreement No. 290492), in which the authors were partners, and which conceived the notion of employing resilience strategies against surveillance systems (see http://irissproject.eu/). In this article, we develop further an analysis of resilience to surveillance.
}

agenda of neoliberalism (Neocleous, 2013a, p. 7; see Chandler, 2013b; Neocleous, 2013b). Recent debate over the usefulness or, conversely, the danger, of adopting a "resilience" approach has taken place in the context of international relations discourse, and specifically with reference to liberal intervention to solve a range of local and global problems (Chandler, 2015). Yet Bourbeau, who notes the proliferation of "resilience" analysis in many fields, observes that in the literature on world politics, security and "securitisation", "there is very little coherence and consensus as to the nature and substance of resilience. The term is employed but rarely unpacked, let alone theoretically analysed" (Bourbeau, 2013, p. 3).

Although the present article is situated broadly within the study of security, we do not aim to enter the current debate on the plane inhabited by its protagonists. Whilst borrowing conceptual elements from some of those engaged in the latter, we aim-in Bourbeau's terms-to analyse "resilience" theoretically in order to use it in the context of surveillance, which we believe is a novel application. This is done in order to contribute to understanding the effects of surveillance. Although surveillance practiced in aid of (national) security or public safety is indeed a threat to desired and desirable personal and social values, we are also sceptical about easy assumptions about the reality of a "slippery slope" that demands only resistance.

We thus explore societal resilience to the threats to democracies posed by the current mass surveillance of communications and other applications of surveillance technologies and practices. This exploration is done through modelling resilience to surveillance, which also embraces "sleepwalking" into a surveillance society and "waking up". Surveillance itself is a resilience tool wielded in government policy, used instrumentallyand discursively justified-to increase collective, individual, or infrastructural security against certain threats, such as terrorism or breakdowns of public order. However, despite the supposed benefits of surveillance as part of a resilience strategy in the face of threats, surveillance's prevalence, intensity, and use of specialised resources including access to personally identifiable information may actually erode privacy along with a host of other "public goods": associated rights, freedoms, ethical principles, security, and other values that it is designed to protect, including democracy itself (Raab, 2012; Raab, 2014). In this erosion, surveillance may exemplify the "dark side" of resilience (Bourbeau, 2013, p. 4).

These prospects of threat and response are examined through the novel visual presentation of possible alternative trajectories. The innovation of this portrayal rests, however, on the fairly well-established conception-that we share with others (see Bourbeau, 2013, p. 7)-of resilience as process and not only as a label for a set of qualities or properties of an individual, 
group, or society deemed to be "resilient". The theoretical possibilities outlined by these trajectories embrace all the engineering, ecological, and socioecological subtypes of resilience sketched by Bourbeau (2013, p. 9, Table 1), and as such, rather than rely on a singular definition of resilience, we present resilience as an overarching term within which the different subtypes may come into play. Turning the tables on the construction of surveillance as resilience to a conventional array of threats to security and safety, the article also further develops the argument that the practices and policies of resilience can be used against surveillance itself, exploring how societies may remain democratic in the face of what some writers have described as the deeply negative impacts that surveillance practices otherwise might have (e.g., Lyon, 2003a, 2003b; Čas et al., 2015; Raab et al., 2015; see also Wright \& Kreissl, 2015).

Whilst privacy is the value, right, or public good most frequently said to be implicated in the employment of surveillance for national security or public safety, we do not assume that "privacy" has a singular, easily grasped, consensual meaning. It is commonplace in the literature on privacy to construe it as a cluster or "family" of values (e.g., Solove, 2008) that are prized for a variety of instrumental or intrinsic reasons, and that may be differently implicated in different normrelated contexts (Nissenbaum, 2010). There are several discernable types of privacy, each associated with one or more relatively distinctive principles, rights or freedoms, including dignity, autonomy, freedom of expression, and several others that form part of the familiar canon of individual rights and public goods inherent in liberal democracy (Wright \& Raab, 2014). Our analysis of what is at stake in the deployment of surveillance embraces, in general terms, any or all of these. There is no space presently to disaggregate this understanding and to discuss each among the variety of public goods; we highlight the consequences of surveillance for privacy and security because these are the values that are most prominent in current discourse and policy.

The central arguments of this article are that the concept of resilience can usefully be applied to the study of surveillance; that resilience cannot be assumed to happen, and may in fact fail; that several different outcomes are indeed possible; that the diagrammatic approach we demonstrate usefully offers a way of incorporating different subtypes of resilience (e.g., "bouncing back") within a unified umbrella framework; and that our diagrammatic approach facilitates the representation and modelling of different scenarios and outcomes. The article's argument develops in three steps: it (1) refers to some existing models of resilience and abstracts them from their specific previous contexts before (2) developing a more varied and general model of resilience. It then (3) applies this specifically to the topic of surveillance.

\section{Resilience: Some Examples in Discourse and Practice}

The concept of "resilience" is identified in all kinds of natural and social phenomena where threats to integrity and identity are faced by physical objects, social goods and ethical values, or social relationships. Persistence and change are the resultant and alternative states of a host of small or large measures taken in response to, or in anticipation of, the challenges that are posed, although whether something is deemed to have persisted or changed-and how much-is not necessarily objectively determined: it is often a matter of subjective perception and conventional agreement or disagreement. This is a generic problem in the analysis of system change or persistence, and is inherent in, for example, the understanding, within policy studies, of incremental (or intra-structural) and large (or fundamental and structural) change (Braybrooke \& Lindblom, 1963, p. 62 and Chapter 4).

Nevertheless, while "resilience" is held to be a widely-applicable concept, its meaning as well as the practical measures it indicates are disparate. The latter point in different ways to the means of protecting, detecting, and responding to the consequences of threats, attacks, disasters and other adverse events. We do not attempt to define the term precisely, although some of its most important connotations are germane to our further analysis and are conveyed in section 4. Some examples of resilience, threat or attack in different contexts and domains can be found in official documents, and are briefly indicated here. Documentary materials drawn from UK government departments include emergency planning (UK Cabinet Office, 2013), cyber security (UK Cabinet Office, 2011a), community resilience (UK Cabinet Office, 2011b), and counter-terrorism strategy (UK Home Office, 2011). Some UN documents concern global sustainability and development (United Nations SecretaryGeneral's High-level Panel on Global Sustainability, 2012), disaster risk reduction (UN System Task Team on the Post-2015 UN Development Agenda, 2012), pandemics and health (Ban, 2009), human rights (Yusuf, 2012), counter-terrorism (UN Security Council, Counter-Terrorism Committee (CTED), 2013), and crime-prevention (UN Commission on Narcotic Drugs/Commission on Crime Prevention and Criminal Justice, 2010). Several points can be derived from this very selective canvass:

- "Resilience" is sometimes undefined but refers to a coherent set of objectives and implementation measures in the face of human and natural threats to vital interests such as national security, food supply and community functioning.

- The resilience strategy relies upon planned, coordinated efforts across organisations at different 
levels, and among participants with defined roles and responsibilities.

- "Resilience" enjoys a certain political appeal, possibly because the term suggests strength, robustness and fortitude.

- "Resilience" is also attractive to administrators, perhaps because it involves skills in problem analysis, strategic planning, and policy implementation.

- The meaning of "resilience" requires interpretive skills because it is not always evident, although its connotation may be clear in terms of strategy and practical measures; however, "resilience to surveillance" is more elusive.

- Even when the term is not explicitly used, it remains possible to construct a plausible scenario that identifies the threat, what is threatened, and how the threat can be countered through preventive or remedial measures.

- Preventative and preparedness measures-not the same thing-loom large across fields where threats or adverse events vary in terms of their inevitability, and therefore in the nature and dynamics of resilience.

Most of the uses of the term are with regard to national or community security and safety in the face of natural or man-made disasters and threats in some near or far future, or with regard to strategies for economic and social development. In some examples, the use of surveillance, including monitoring or other means of information gathering and social control, is considered to be part of a resilience policy or strategy.

A further relevant observation points up a distinction between resilience as a property of a society, community or an individual, and resilience as the activities undertaken to bounce back or to anticipate some threat. For example, it is possible to distinguish between two different meanings of the term "community resilience". The first is the kind of localised planning and contingency measures often encouraged by government as a means for localities to cope with sudden adverse environmental conditions or terrorist attacks, and to work alongside "first responders". The second kind is the more intrinsic or "organic" quality of psychological or community social solidarity evident in response to certain adverse events, suggesting that far from being fractured by the adverse event, individual psyches and communal bonds are resilient to damage and may even be part of a wider community-rebuilding process (see also Hall \& Lamont, 2013a).

Various theories may be found in the social sciences-for example, sociology and criminology-to account for communal "organic" resilience. For example, Durkheim (1984 [1893], pp. 53-67) famously characterises fundamental societal ties in terms of "social solidarity", comprised both of social-economic interde- pendence on others and of shared moral values. More recently, Putnam (2000) has sought to explain why certain places or regions display greater civic vibrancy, arguing that factors such as social networks (and voluntary associations in particular) build trust and links between local people, and Sampson (2008) has argued that the concept of "collective efficacy" can explain how mutual local support may be used to achieve particular collective goals. In each case, these theorists have sought to explain empirical differences in social cohesion, both between different places and over time, finding that such cohesion is by no means inevitable. While community resilience is often assumed to be desirable, its capabilities could be used by government as a pretext for transferring responsibility for contingency management to the local level, and could even perhaps induce communities to learn to withstand events or situations that they should not have to tolerate (see also Walklate \& Mythen, 2015, Chapter 6).

We now highlight at greater length a contrasting example-the study of dictatorial and post-dictatorial regimes-that relates to an overtly "political" context rather than one concerning natural or man-made disasters or law-enforcement. Here the focus is upon how, and to what extent, societies show signs of resilience in relation to the exercise of political power and the distribution of resources. In this illustration, "resilience" becomes more easily seen as neither necessarily a "good thing" nor necessarily a "pro-security" concept. Similarly, Bourbeau $(2013$, pp. 7-8, 10) refers to resilience's undesirable "dark side" and its dependency on context; Marx (2015, p. 16) makes a similar argument in relation to "resistance" and to "security" in general. Seeing these regimes in transformation also brings to light concrete developments that will be exemplified on a more abstract and conceptual level later in this article.

In the Soviet era in East and Central Europe, the wide range of political regimes experienced periods of change from dictatorship through transitional phases leading towards forms of democratic system. This transformation brings into view a tension between the political regime and the society, casting light on different meanings and manifestations of "resilience": societal resilience towards the dictatorial system, and the resilience of dictatorial systems themselves towards political and societal changes and towards external international pressure. Citizens, groups and institutions developed a resilience capability towards changes at various levels.

At the individual level, for example, families from the pre-war upper middle class kept their large flats if they formally accepted expropriation and nationalisation of the flats and formally registered co-tenants who had never actually lived there. Another resilience strategy of certain educated families was to commission forged paintings of famous painters from skilful local artists, since preserving and storing artworks acknowl- 
edged as part of the cultural assets of the county, for the preserving and storing of which the state galleries had no space, made them eligible for possessing an extra room in their flats. Tolerance shown to dissident groups and their samizdat (clandestine) publications contributed to resilience of the system and its citizens. For citizens who accepted the regime, family life and personal economy were developed through small-scale semi-private enterprise and informal economic networks. Those in opposition in underground movements developed resilience through a variety of means. In addition, the degree of a regime's repressiveness, and its use of ubiquitous surveillance in the era of the Stasi, the Securitate and similar organisations shaped opponents' behaviour and resilience. These and other characteristics enabled the regimes to reduce national and international tensions, to adapt to changing environments, and to resist shock-like impacts.

In the period of democratic transformation, the "Velvet Revolution" (Czechoslovakia) or the "rule-oflaw revolution" of 1989 (Hungary) can be seen in terms of structural resilience that retained the legal and administrative framework. There is a strong tradition of resilient personal survival through social and political influence spanning transitional regime changes. Members of the former political and economic elite retained their influence by taking over state-owned companies, and the discredited secret services soon reconsolidated themselves. Even where their leaders were replaced with trustworthy pro-democratic people, many personnel remained in office, together with their organisational culture, and adapted to the changing environment. In some countries in the post-dictatorial period (e.g., Hungary), new organisations, the enforceability of individual rights and freedoms, and the capitalist economy created a window for the establishment of new institutions and international relationships. However, it is not clear whether the resilience of all social strata has persisted and become stronger. Some new democratic political organisations proved vulnerable and short-lived. Trade unions became marginalised, and the position and living standards of the unskilled and the intellectuals declined.

Societal resilience specifically towards surveillance in the post-dictatorship era also deserves attention. After the changes, the fear of the regime was replaced by a fear of crime. Societies under long authoritarian rule have virtually skipped the period of democratic modernity and jumped directly into the surveillance culture of postmodernity (Los, 2002). The lack of historical experience resulted in increased vulnerability and decreased resilience towards new forms and technologies of surveillance, as individuals became more susceptible to business and marketing offers and industry-driven surveillance (Szekely, 2008). In those former dictatorial regimes where personal and family life were more resilient, and although private surveillance was not conceived as potentially harmful, suspicion against state surveillance remained high.

The lessons learnt from this non-democratic and transitional context are that:

- In the perspective of democracy, a resilient dictatorship, in which non-democratic forms of political life and the careers of privileged elites may be able to survive shocks and defeats, is clearly not "good", whereas civil-societal resistance ( "resilience") to the dictatorship's surveillance strategy appears politically desirable.

- The general question, "is resilience desirable?" is therefore germane in any example.

- More generally, it is important to look at the passage of historical time in analysing the sequences of adverse events and responses in order to conceptualise resilience as a trajectory.

All the above illustrations show the diversity of resilience practices and meanings in different contexts. Our argument here is (1) that resilience has become a major theme in UK and UN government policy today, particularly in relation to security matters; (2) that there are various political dimensions to this; and (3) that whatever one's political evaluation of how resilience is operating in a given area, the twin policy themes of (a) assessing the "amount" of resilience present and (b) seeking to increase this through developing better processes seem very powerful from a policy-making perspective.

Before we focus upon the domain of surveillance as the set of specific events and practices towards which resilience may be oriented, we first explore the theoretical grounding of the concept of resilience and locate our own efforts within its literature.

\section{Theoretical Underpinning of "Resilience"}

The concept of "resilience" has certain linkages with conceptual and theoretical writing on general systems and cybernetics - based on the analysis of communication and control-that discuss natural and social processes involving changes of state or restoration over time, threats to existing states of affairs, and/or interactions between actors and the "world" they seek to change or regulate. There is only space here to draw attention to the heuristic value of such conceptual frameworks for deriving points or questions that may be useful in the analysis of resilience.

General systems theory posits the notion of a system and its environment, and analyses the relationship between parts of a system, their contribution to the whole, and the relationship of the system to its environment(s) (Demerath \& Peterson, 1967; Deutsch, 1963; Easton, 1965; Emery, 1969; Parsons, 1951; Wiener, 1954). Changes can be generated internally to a 
system or as an effect of its environment. Central to such theory are concepts such as equilibrium, stability, homeostasis, and the normal states of systems in terms of their internal organisation or in relation to their environments. Systems theory and cybernetics are replete with themes and concepts of organisation and disorganisation, the degradation (entropy) and reinforcement of states of being, adaptation, stability and instability, order and chaos, flexibility and rigidity, communication, information and control, selforganisation and feedback, and many more. They provide a conceptual language for talking about how systems maintain themselves, change, grow or die; all these states are relevant to an understanding of resilience. Perhaps even more difficult-and interesting - to analyse are cases where a system becomes utterly transformed into something "new"; the dictatorial and post-dictatorial example may be seen in this light. The application of systems thinking to human affairs is typically done not only to describe social or political phenomena, but to contribute prescriptively to change and improvement in the latter in accordance with ideals and values that are, of course, themselves open to debate.

A system may not only react to environmental effects by changing its internal properties or organisation, but also act on and change its environment, bringing about a new relationship or a new equilibrium. Several "resilience" authors suggest this, and their observations are germane to current attempts to clarify the concept and make it relevant to contemporary debate and practical application, as we shall see. Holling, a leading theorist of ecological resilience, calls the two approaches "analytical" and "integrative" (Holling, 1998). White and O'Hare (2014) distinguish between "equilibrist" and "evolutionary" resilience; Longstaff's (2005, p. 27) similar distinction is between "engineering" (status quo maintenance) and "ecological" (state change) resilience; and Taleb's (2013) is between "antifragile" and "resilience". In the business context, Hamel and Välikangas's (2003) terms are "strategic resilience", involving "continuous anticipation", and "dynamic reinvention". More pessimistically, Walker and Salt (2006) note that "complex adaptive systems can...have more than one "stable state'"; depleted fish stocks may not be resilient enough to recover (p. 36); and change may be slow and unnoticed (p. 10). Feibleman and Friend's (1945) comprehensive framework enables the location of resilience within a variety of stances that relate to the nature of the systems that respond to environmentally induced changes or stimuli.

In these approaches, outcomes may be achieved through processes that include communication, flows of information, learning (Deutsch, 1963) and awareness of the entity's internal state and of the configuration of its environment, and by means of instruments for discovering and for affecting salient parts of the external world (Hood, 1983). These may all be seen as part of a repertoire for being resilient in the face of threats, whether by anticipating and avoiding these risks or by responding when they occur. We cannot fully explore these processes here, or relate them systematically to resilience to surveillance. However, drawing upon such constructs and concepts helps in generating and answering important questions about the resilience of a social system-including its democratic values and practices - to adverse events, whether these be external or internally generated ones such as are posed by systems of mass surveillance.

Relating to the points derived from the examples described earlier, many questions could be posed, inviting deeper development of resilience strategies, and illustrating the way in which theoretical and conceptual analysis affords a purchase on the kinds of processes that are of particular interest to us in focusing upon the threat posed by the mass surveillance of communications in particular. However, space permits only a few basic questions here; these are prompted by high-level approaches but are deliberately re-orientated towards the political and social frame of reference in which we seek to analyse resilience phenomena. The current questions include:

- What analogies can be drawn from the processes of threat and responses in other concrete systems in order to model surveillance-resilient processes?

- Is the threat carried out suddenly or incrementally?

- What "constitutive public goods" are at risk in liberal-democratic societies, and what sustains them?

- Do resilient adaptations result in the maintenance or restoration of pre-surveillance levels of public goods, or is a new equilibrium established at lower or higher levels?

Further questions - not considered here-would include:

- How vulnerable are these public goods to the threat of surveillance?

- Can we describe, in equilibrium terms, the relationship between a liberal democratic society and the state(s) in its environment?

- How much (and what forms) of surveillance threaten what public goods?

- How severe is the threat, and what public goodssustaining social and political processes and functions are threatened?

- What is the society's degree of flexibility and its potentiality to adopt one or another response to external threats?

- How does the system (i.e. society) learn about the potential threats to its public goods, processes or functions?

- Can democratic societies take anticipatory action 
to prevent these threats from occurring or to mitigate their likely effect?

- What are the internal (re-)organisational and resource prerequisites to anticipatory and selforganising activity to prevent or mitigate threats?

- Does such action include only internal change in culture, structure and behaviour, or does it also include efforts to inhibit surveillance at source?

\section{Modelling Resilience}

We have already observed that there is now a sizeable and growing literature on resilience, featuring various definitions, though also some common conceptual language (Clarke, 2013). A document on food security defines it as "the capacity of agricultural development to withstand or recover from stresses and shocks and thus bounce back to the previous level of growth" (The Montpellier Panel, 2012, p. 11). Cognisant of that document, another one in the same field says, more generally: "Resilience is the ability of an individual, a household, a community, a country or a region to withstand, to adapt, and to quickly recover from stresses and shocks" (European Commission, 2012, p. 5). It continues:

The concept of resilience has two dimensions: the inherent strength of an entity-an individual, a household, a community or a larger structure-to better resist stress and shock and the capacity of this entity to bounce back rapidly from the impact....It requires a multifaceted strategy and a broad systems perspective [...and] calls for a longterm approach (European Commission, 2012, p. 5; emphasis in original).

Within academic literature, Chandler (2012, p. 217), for example, has defined resilience as "the capacity to positively or successfully adapt to external problems or threats". Writing from a more psychological perspective, Luthar, Cicchetti and Becker have similarly defined resilience as "a dynamic process encompassing positive adaptation within the context of significant adversity" (Luthar et al., 2000, p. 543; cited in Bourbeau, 2013, p. 7). Hall and Lamont (2013b, p. 13) define "social resilience" as "an outcome in which the members of a group sustain their well-being in the face of challenges to it". There has been some debate, however, as to what the nature of all these forms of resilience adaptation might be.

References above to the work of White and O'Hare (2014) and to Longstaff (2005) showed that one way to understand the nature of "resilience", and to distinguish between different kinds of resilience, is to consider whether the system reverts back to the status quo or instead changes to a new state. Similarly, the colloquial term "bouncing back" is often used to capture a quality of resilience, connoting recovery to the prior state of "normality". However, as Folke (2006, p. 259) has argued, resilience may also involve evolution towards a "new normality" or perhaps a new equilibrium, comprehensible in terms of the theoretical underpinning discussed above, and which one might term "bouncing forward". In a variant of the twofold distinction, Bourbeau $(2013$, p. 8) draws a threefold but perhaps broadly similar distinction, namely between engineering (equilibrist) resilience, ecological resilience (system continuity), and socio-ecological (emergent or adaptive) resilience. He then goes on to suggest a revised threefold distinction, namely between "resilience as maintenance", resilience as "marginal adjustments", and resilience as "renewal" or "remodelling" (2013, p. 12). Bourbeau consequently defines resilience "as the process of patterned adjustments adopted by a society or an individual in the face of endogenous or exogenous shocks" (2013, p. 10). Additionally, and presumably in order to distinguish the analysis of the workings of resilience from resilience itself, he proposes the new term "resiliencism", which he defines as "a conceptual framework for understanding how continuity and transformation take place under these circumstances" (2013, p. 10; see also Bourbeau, 2015a).

Another way of approaching the question of how best to define or characterise "resilience" is to identify the various different strategies or techniques it typically employs. An interesting feature of resilience strategies is that they seem to involve a combination of forward-looking measures attempting "to anticipate, prepare for, and, as far as possible, avoid the worst excesses of the next disruption" (Cho, Willis, \& StewartWeeks, 2011); measures, such as resistance, designed to combat current events; and learning, recovery or change measures in response to adverse events that have already occurred. Moreover, it is clear that we need to distinguish between resilience as a strategy and resilience as a description of empirical reality. Furthermore, we agree with Bourbeau that, especially in relation to the second of these, rather than imagine resilience as being wholly effective or ineffective, it makes more sense to consider it as a matter of degree. In a subsequent section, we explore these various elements further and propose a framework within which various scenarios can be modelled, including ones that are not normally entertained in discussions of resilience, namely where it fails. Before that, however, we turn to a brief discussion of the differences but also the relationships between resilience and resistance.

\subsection{Resilience and Resistance}

Resilience is not a one-off performance, but a sustained and systematic process that includes capacity-building institutional and procedural development. It partly overlaps with "resistance", an important but relatively unexamined concept in surveillance studies, involving indi- 
vidual and group opposition, protest, and defensive measures, but is a quite different process and not synonymous with it (on the issue of "resisting surveillance", see Bennett, 2008; Fernandez \& Huey, 2009; Introna \& Gibbons, 2009; Lyon, 2003b; Martin, Brakel, \& Bernhard, 2009; Sanchez, 2009; Wells \& Wills, 2009; Wright \& Kreissl, 2015). In relation to the opposition to surveillance, privacy and other human-rights advocates might ask why the adoption of "resilience" terminology and frameworks should be preferred over existing discourses and strategies involving "resourcefulness", "risk management" and, in particular, "resistance". Evans and Reid (2013) lament the conflation of "resilience" and "resistance". They abhor the de-politicisation of "resilience" in which individuals are exhorted to abandon resistance and to adapt to, rather than to oppose or politically transform, situations of insecurity and adversity. They see this as a "nihilistic" capitulation to liberal regimes that thrive on the insecurity of others.

Although we do not share these authors' confidence in "resistance" as the preferred stance, we fully acknowledge the many overlaps and linkages between it and "resilience". However, we seek to demonstrate that the conceptual and practical apparatus of resilience identifies various discrete components that might also inform future resistance strategies; it offers a distinctive holistic approach of a kind not always readily captured in the notion of "resistance". Moreover, in some languages, "resilience" does not have a straightforward equivalent. But even where there exist separate terms for resilience and resistance, actions aimed at withstanding shock-like adverse events can have a resistant and resilient aspect alike. According to popular conception, resistance can be associated with a rigid entity that undertakes an aggressive or even counterstriking action to defend itself, while resilience may evoke more flexibility, as systems theory indicates. In many cultures, and in the history of oppressed peoples, heroism demands resistance. In other cultures and movements, "passive resistance" or "turning the other cheek" are the principled and valued responses. Sometimes, there may be a dramatic choice.

At a general level, although both notions incorporate elements of prediction and prevention, resistance can be seen as a response that concentrates on the present; tries to avoid changes and preserve the existing state; emphasises the political dimension of the struggle; and sometimes uses radical solutions such as pre-emptive strikes or self-destruction. Resilience, on the other hand, refers to a broader and sometimes more bureaucratic range of measures deployed to try to cope with changes, and that may learn from the past and plan for the future as well as deal with the present. Thus the resilient entity is not only able to recover but also to develop ways to exist within adverse circumstances, and also to prevent future adversity.

Bourbeau (2015b, pp. 17-18) has recently suggest- ed a further way in which resilience and resistance, while different, are interrelated, namely that the capacity to resist, especially on an on-going basis, might be thought to require some resilience capability as a prerequisite for success. For example, the capability to mount resistance strategies could be seen as reflective of an entity exhibiting resilience; and the ability to withstand and bounce back from the likely setbacks involved in a resistance struggle also seem "resiliencelike". Lastly, a successful resistance measure may even lead to a new state of affairs, or "bouncing forward".

The question of process also points towards resilience's inclusion of a learning component, another complex matter to be explored. It is one of the steps in a temporal sequence that is recommended for building resilience in a specific domain such as agricultural development, and in wider policy discourse. This includes activities to anticipate, survey, prevent, tolerate, recover, restore and learn. As we will soon see, a resilience model used in the agricultural development field (Conway, Waage, \& Delaney, 2010, p. 309) is helpful because it neatly summarises the content of resilience processes and offers a dramatic visual representation of what may typically take place over time. Other terms used in the agricultural setting are withstand, resist, handle, absorb, adapt, response, resume, optimise, innovate, reconstruct, renew, and persist. In the field of disaster-reduction, the concept of vulnerability is also important: "[t]he conditions determined by physical, social, economic, and environmental factors or processes, which increase the susceptibility of a community to the impact of hazards" (International Strategy for Disaster Reduction (ISDR), 2004, p. 16).

Armed with such process-related terms, it is possible to model an approach to resilience to surveillance drawing upon such terminology to depict a continuous process embracing:

- anticipatory, preventive measures to mitigate the harms that may be brought about through surveillance;

- measures to absorb, resist or withstand the threats posed by surveillance; and

- post-event measures to recover and to learn how better to anticipate and/or to cope with harmful surveillance.

How the concepts are configured into relationships and sequences is a crucial question that will be sketched later on, but the details of this must be left for another time. Whilst these high-level concepts apply generically to situations of resilience, it is necessary to develop models that correspond closely to the circumstances of the different domains of application, but-againdetailed demonstration must be deferred. For example, some of these domains afford greater possibilities of anticipation and prevention than do others, and the 
part played in resilience respectively by society and by state institutions will also vary.

\subsection{The First Step: Identifying the Components of Resilience}

In this section, we explore some different sequences of adverse events and system responses, in order to highlight various possible outcomes in which a system does or does not exhibit resilience. Our discussion begins by taking a model from a particular domain, then generalising it, before considering its applicability to the question of societal responses to mass surveillance systems specifically. We use a series of diagrams to help illustrate the processes at work.

The heuristic diagram in Figure 1, drawn from work on agricultural development (Conway et al., 2010, Figure 9.9), shows a simple resilience sequence.

We will supersede this diagram with ones that consider surveillance as the disruptive phenomenon, but it is useful to refer to it and its definitions in showing the general, cross-domain conceptualisation of resilienceinvolving both preparedness and response ${ }^{2}$-and the part played by the concepts "stress" and "shock". In this construct, "stress" is defined as "a regular, sometimes continuous, relatively small and predictable disturbance", and a "shock" as "an irregular, relatively large and unpredictable disturbance" (The Montpellier Panel, 2012, p. 11), although it would be advisable to disaggregate each definition in order to show differences in size, predictability and continuity. The terms

${ }^{2}$ Conway et al. (2010) identify and diagram a further important element, "countermeasures", representing the deployment of measures to address the negative consequences of stresses or shocks that have become apparent (Figure 9.8). The effectiveness of countermeasures is not assumed, and subsequent scenarios, for better or worse, can then be sketched. indicated in the x-axis, from "anticipate" to "learn", signify different activities that are important in resilience, albeit not necessarily in a clear sequence.

However, as this diagram derives from a developmental context, the expectation of a rising slope, especially as the target for recovery, cannot be simply transposed to a model tailored to a surveillance-andhuman-rights context, because it is not obvious that rights protections can be confidently expected, or planned, to improve steadily over time. Similarly, from the perspective of surveillance and rights, the upward slope may indicate an ambiguity, namely whether the model represents an ideal (that it is desirable for "development" to increase over time) or whether it purports to represent reality, albeit abstractly (that societies typically are developing over time). Usefully, the diagram does not show only the course of a relatively simple "bounce-back", perhaps through some meandering, to the trajectory of development, but also envisages possibilities of indefinitely longer drift to lower levels where loss-de-development-replaces recuperation; in other words, the system has failed to be resilient.

We particularly recognise the potential of the concept of "resilience" to become, as Béné, Godfrey Wood, Newsham and Davies (2012) put it, a "form of integrating discourse" able to rally an "increasing number of people, institutions, and organisations under its banner, as it creates communication bridges and platforms between disciplines and communities of practices, and offers common grounds on which dialogue can then be initiated between organisations, departments or ministries which had so far very little, or no history of collaboration" (p. 12). Such bridges and platforms are crucial to countering the detrimental effects of surveillance, ensuring effective respect for public goods and at the same time protecting people and communities.

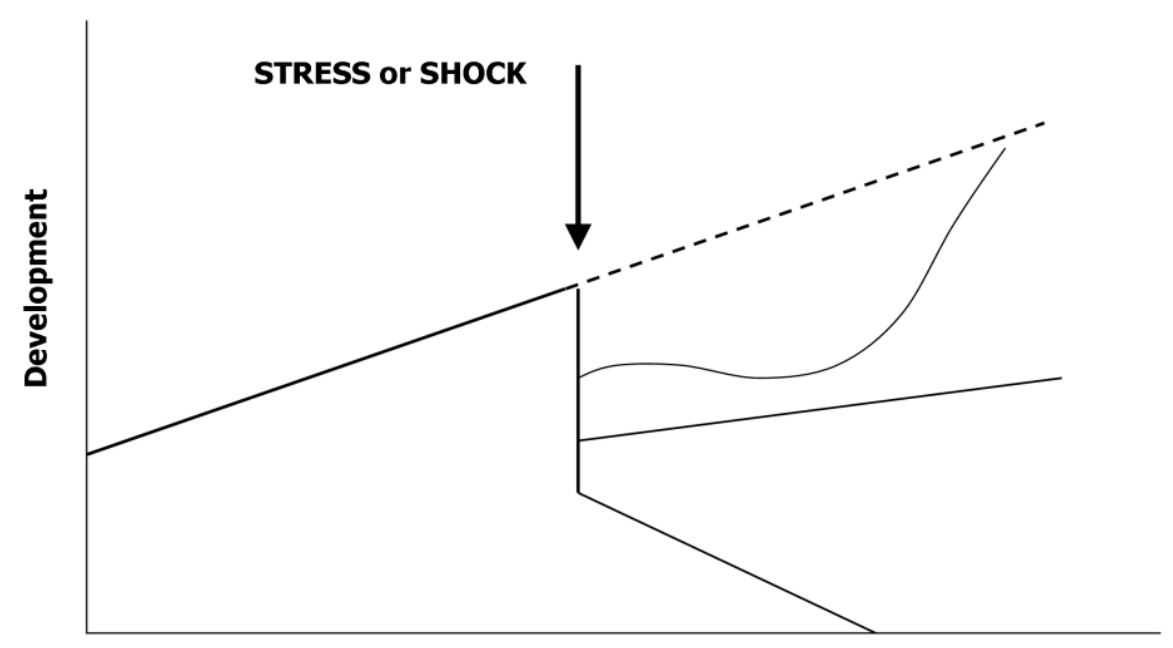

Anticipate Survey Prevent Tolerate Recover Restore Learn

Figure 1. Agricultural development model of resilience. Note: A similar diagram was used in IRISS Deliverable 6.1, and was adapted from The Montpellier Panel (2012, p. 11). 


\subsection{The Second Step: Developing and Exploring the Re- silience Framework}

With this in mind, we take further steps in the direction of resilience to surveillance by means of revised models. Figure 2 depicts two axes: public goods, and time. The $x$-axis is re-labelled "time" because this makes explicit what is implicit in the original model, namely that the diagram represents a temporal flow, and that its constituent elements (anticipate, survey, etc.) may be thought of as associated with different moments in relation to the stress or shock event. The $y$-axis is relabelled "public goods", in order to generalise the model's applicability. Loader and Walker (2007, p. 145) argue that an expanded concept of "public good" can usefully be applied to the study of security by including not only shared societal goods such as liberty or freedom of expression, but additionally, by seeing such a good as a "constitutive public good"; that is, a societal good understood as an integral and essential element of society itself. We contend that this expanded concept can similarly be applied to the study of resilience in general, as well as to privacy in particular when it is threatened by, for example, "national security" surveillance. Public goods can refer to any "good" of potential fundamental benefit, but here we are particularly interested in goods relating to freedoms, liberties, rights, democracy, security and privacy: the ones that are typically impacted by surveillance. A further advantage of using the term "public goods" is that it can refer both to their realisation in practice, and the vigour with which they are valued as societal values.

In Figure 3 we introduce a new element, the "ideal level" of the desire for, vis-à-vis the "real level" of public goods. We represent here the ideal level (i.e., how much a public good is desired or valued by society) as a horizontal line, hypothesising an ideal Western constitutional democracy where the desired level of public goods is constant. We also label the three scenarios represented in the original model (full recovery, partial recovery, and non-recovery).

As noted above, while there are some similarities between the concepts of "resistance" and "resilience", there are also important differences. Our revised model enables us to illustrate this distinction through a separate abstract model for resistance, which helps to distinguish it from the various cases of resilience (Figure 4).

Whereas Figures 1-3 model resilience in the face of the occurrence of a single major event, Figure 5 models resilience both in the face of incremental, "creeping" threats to public goods, as well as in relation to a single major event or a small but culminating event that "breaks the camel's back". Figure 5 thus better models resilience in relation to surveillance, in which surveillance threats may be incremental and gradual, or sudden and dramatic, although these properties are not unique to surveillance as a threat. It should be noted, therefore, that the model in Figure 5 is a general one, potentially also applicable to the threats to security that give rise to surveillance. It is possible to make advances on this diagram through other ones that depict further dimensions of resilience to surveillance, and that highlight other important considerations and questions about the path of resilience that pertain not only to the surveillance context but to others as well.

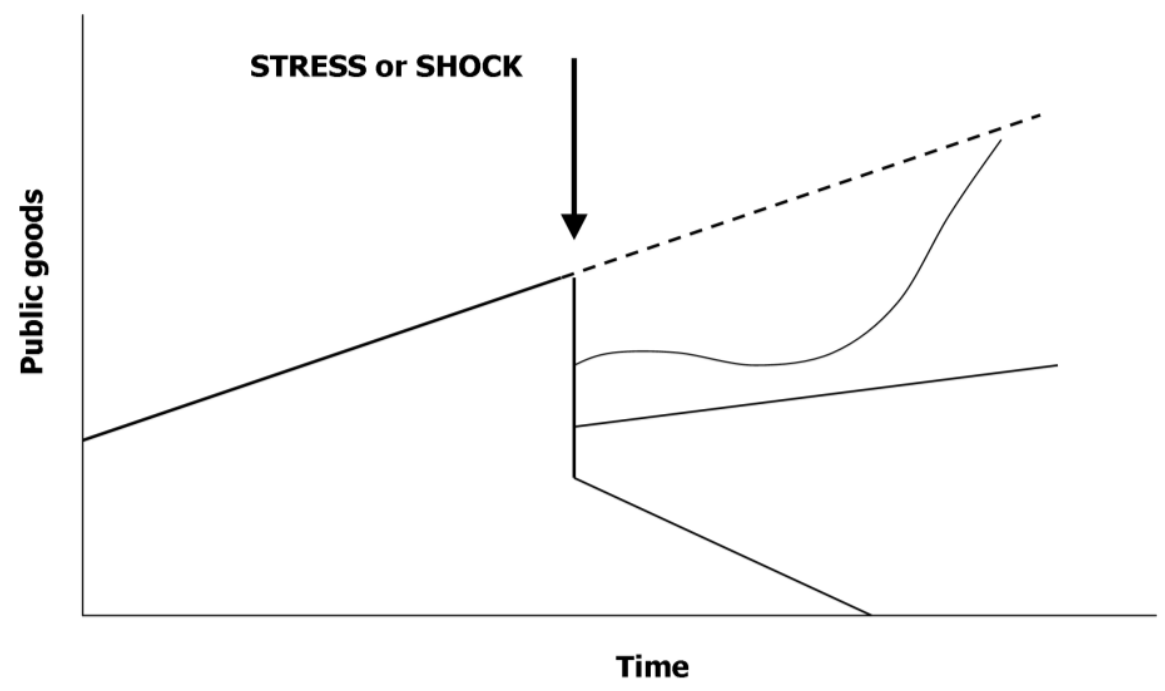

Figure 2. Relabelled Conway diagram. 


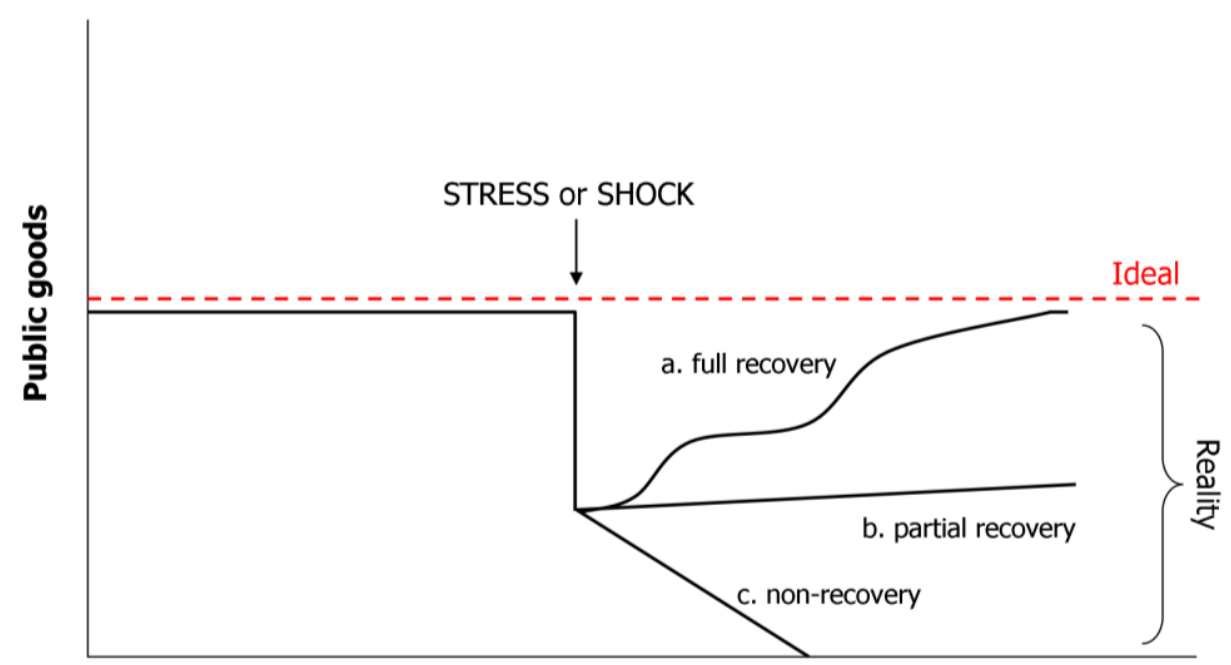

Time

Figure 3. Modified resilience model.

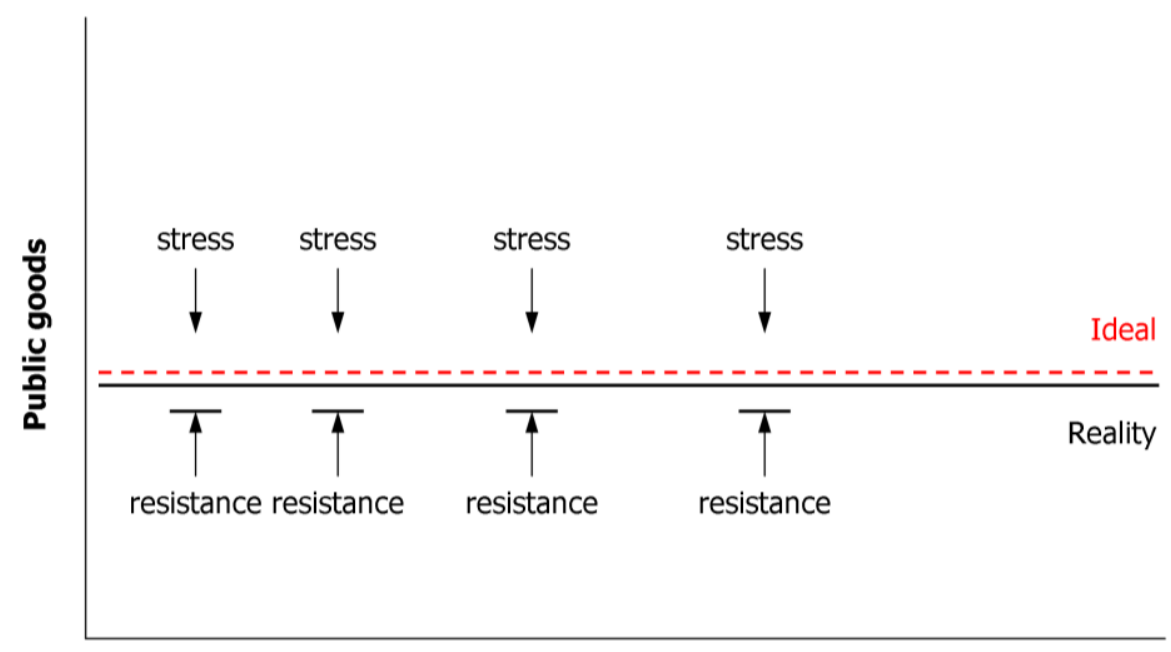

Time

Figure 4. Resistance towards stresses and shocks.

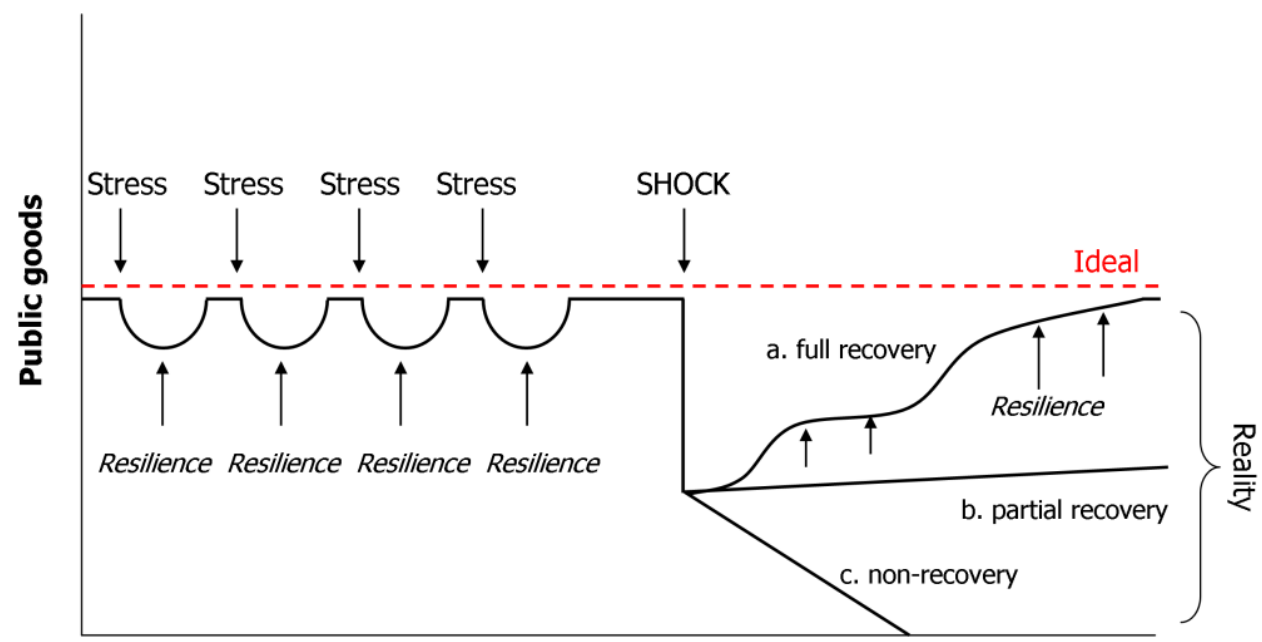

Time

Figure 5. Resilience towards repeated stresses and shocks. Note: An earlier version was used in IRISS Deliverable 6.1. 
In the case of security or agricultural development, stresses or shocks are often modelled as sudden major shock events, for example, a terrorist attack or famine. However, in the case of surveillance, measures introduced that have a deleterious effect on civic society, such as a "chilling effect" on political debate or freedom of assembly, need not be singular or sudden, but may instead be smaller but more sustained. Consequently, this diagram incorporates an additional resilience scenario, showing a series of stresses, each one followed by an episode of resilience, which in the paradigm case restores the public good in question to its prior state, although of course full restoration need not be the case. The diagram also shows a final stress or shock-whether small or large - that has a larger effect on public goods, so that resilience has a more uncertain outcome and may take longer. As in agricultural development, the uncertainty of the outcome is shown by the top line following the "final" stress or shock, and by two further lines that represent the reestablishment of public goods at reduced levels. For the sake of simplicity, the public goods are depicted as fully restored after several stresses prior to the ultimate stress or shock, but other trajectories are possible: one in which the public goods are eroded over time (the line descends); or alternatively where public goods are actually enhanced (the line ascends; to be shown later).

\subsection{A Closer Look at Resilience Elements}

It is not the aim of this article to produce an ultimate, universal definition of resilience, nor to vote for one of the existing definitions (and consequently approaches) from the wide spectrum between specific application areas and the view of Neocleous, who dismissively says that resilience is "all and everything". Nevertheless, in order to understand better the notion of resilience in general and in the context of surveillance, we need to explore its fundamental elements and their reasonable spheres of interpretation, and to highlight at least the most important aspects of these elements. We focus on three such elements: the reference point or normalcy, the time scale in which changes can be measured, and the role of perception.

\subsubsection{The Reference Point or the State of Normalcy}

As has been shown, resilience is generally understood as a "good thing", an entity's positive capacity or strength that enables it to resist stress and shock or to bounce back from the impact. Consequently, stresses and shocks are considered in this context as adverse impacts or events: "bad things" that degrade the original state of the entity. Although in this article we regard resilience as potentially positive, resilience as an abstract notion is inherently value-neutral. Every struc- ture or entity can have the characteristics of being resilient towards external or internal impacts. It is relatively easy to identify those states of entities that are widely regarded as having positive value, while the stresses or shocks to it are seen as negative, and towards which the entity should be resilient. For example, most people would regard food safety as a beneficial state of society, and see floods and droughts as having adverse impacts. It is regarded as positive if the system can mobilise food reserves, thus being resilient towards such impacts. Similarly, there is consensus that a working electricity, waterworks or telecommunication infrastructure is a "good thing". Our war enemies' resilient infrastructure is regarded as a bad thing from the standpoint of our interests.

Even if we consider resilience from our own perspective and interests, in reality most beneficial states are not optimal; the ideal state might only be expected or imagined. However, it is possible to evaluate changes and resilient responses in relation to these suboptimal states, too: in other words, to measure the level of resilience in relation to these realistic situations. If a country's food safety is not optimal, but can bounce back from even the strongest of shocks to the usual, sub-optimal level, it can still be regarded as resilient.

Society as a whole or the groups that constitute it cannot be regarded as homogeneous entities with regard to either the positive or negative nature of the state of normalcy or to the positive or negative nature of the stresses or shocks, as the example of dictatorships showed. For most individuals or social strata a strong stress or shock, such as an economic crisis, can be adverse, yet for others it could be beneficial. This may have a strong impact at a higher level of society, too: it may change power relationships and the social distribution of goods. In such contexts, the formal or informal obligation to be "resilient" may easily be abused or at least used in a questionable manner (Slater, 2014). Since we focus on the social implications of resilience, we adopt the values (public goods) of western liberal democracies. But even within this value system, the same impact may have both beneficial and adverse effects on the same citizens concerned, an example of which is the consequences of ubiquitous surveillance in the developed world.

Finally, the reference point (or reference line in the graphical models, below) is not always stationary: it is changing, even if change cannot easily be perceived because of its slow pace. In addition, the inherent public goods-reflected in the written and unwritten norms governing the life of a social entity-may also change as a result of repeated stresses or shocks. Figure 6 shows an expanded model of resilience with eroding public goods. The vertical axis, "public goods", refers both to the horizontal line that shows the persistence of a good's desirability (the "ideal"), and to the descending line that shows the decline in its reality un- 
der conditions of stress. As our introduction remarks about surveillance suggested, this situation is quite realistic in an environment where citizens become resilient towards security threats but gradually lose their "reasonable expectation" of privacy, autonomy, or dignity due to increased surveillance. ${ }^{3}$

However, it is also possible that repeated stresses and shocks result in an enhanced desire for public goods, perhaps through an increase in social solidarity, institutional organisation, morale, greater awareness, or other reinforcing conditions and factors. Thus citi-

${ }^{3}$ With regard to privacy, the doctrine of "reasonable expectation", a complex and legally controverted concept involving both normative and empirical dimensions as well as contextual understanding of what is "reasonable" in what circumstances (Nissenbaum, 2010, pp. 233-236; Solove, 2008, pp. 71-74) is closely related to the level of public goods depicted in our diagrams, including increases and decreases over time. zens may become sensitised to the detrimental social side-effects of security measures and increase their demands regarding the guarantees of their privacy, dignity, autonomy, etc. in such situations (Figure 7).

Resilience towards security threats may also mask adverse changes affecting certain social groups, or conserve a social-political situation that is far from ideal and prevent it from improving. For example, increased social sorting-a possible adverse consequence of ubiquitous surveillance (Lyon, 2003a)-may be legitimised by the needs of resilience towards security threats and stresses. It is in the face of such challenges that societies may seek to affirm the principle that in a democratic regime even the positive aspects of resilience should not serve as a means to conserve contradictory social or political constructions or inhibit the development of a democratic, rule-of-law society.

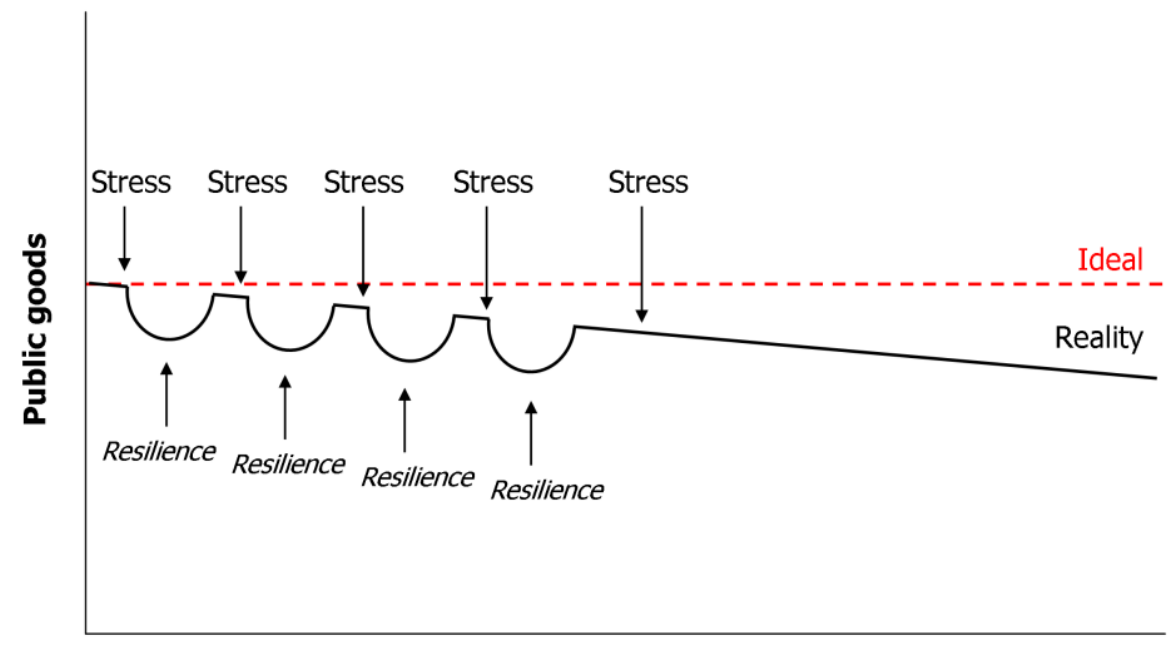

Time

Figure 6. Expanded resilience model showing creeping erosion of public goods.

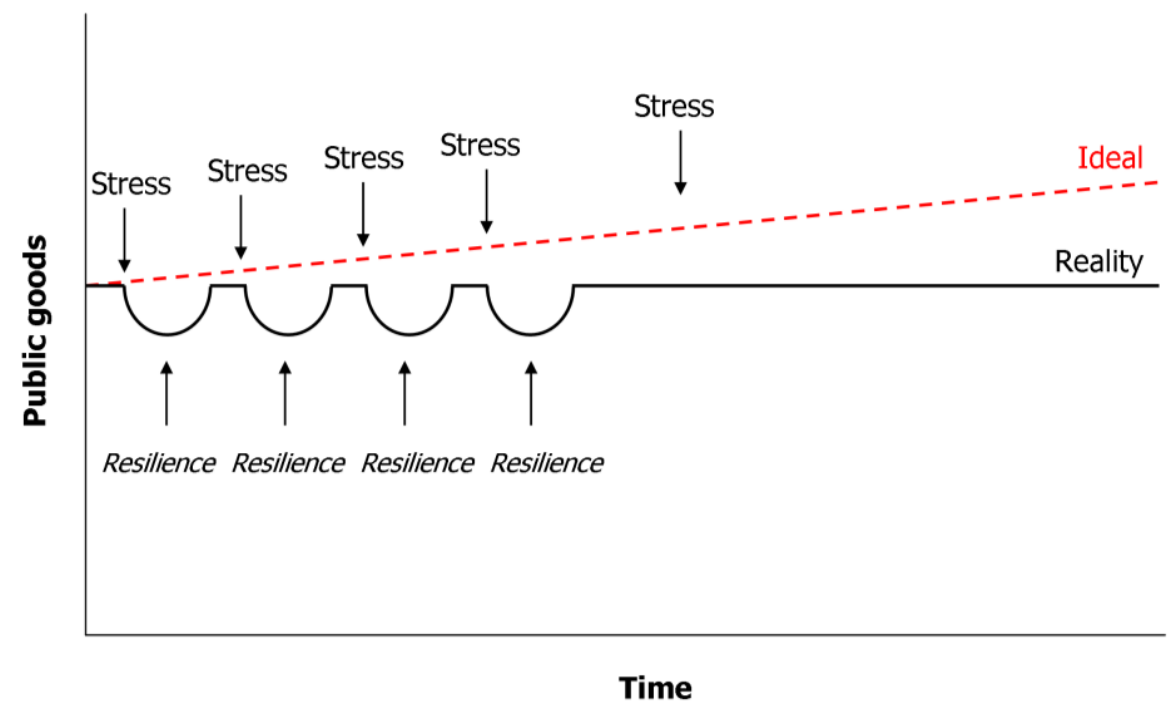

Figure 7. Expanded resilience model showing enhancement of public goods. 


\subsubsection{Time Scale}

The time dimension in the context of resilience is important from two main perspectives. First, if the intensification of stressful adverse changes is too slow to be perceived by social groups or individuals, the impacts will hardly be recognisable; thus we can speak about non-conscious, "instinctive" resilience only (see also the role of perception, below). Second, if the adverse impact is shock-like and therefore recognisable, but if the bouncing-back (or forward) phase is slow or uneven, the effect of resilience cannot be easily recognised. Two types of this second situation can be noted. In the first type, the impact is strong, its consequences are evident, and the recovery also consists of fast but only partial actions; full recovery takes a long period of time. The second type can be observed in the case of long-lasting emergency situations, such as wars or long-term natural disasters. Here the period of stresses and shocks lasts long but the recovery phase even longer; years may pass until one can conclude that society has regained or improved upon its earlier state.

However, if the original state of the society or entity will be restored or surpassed only after several years, or in the life of a new generation, it is debatable-in general systems terms-whether this can be regarded as a new entity, a new chapter in the history of the society, or as still part of the resilience capacity of the original entity (Braybrooke \& Lindblom, 1963). In such situations, therefore, it is necessary to identify those public goods that, even in a changed environment, may represent the ideals with regard to which a society may be considered resilient. In this respect, a post-war country where the economy has been quickly restored, coupled with a dictatorial political regime, can be regarded as resilient in terms of the economy but not in terms of the society or polity, if the country had been a pre-war rule-of-law democracy.

\subsubsection{The role of Perception}

Adverse developments and their impacts, especially in the case of persistent stresses such as ubiquitous surveillance, may remain unnoticed by those affected. When they finally realise the consequences, the moment for diminishing the impact or developing an alternative strategy may have passed. Such a situation may also result in an unnoticed erosion of the "ideal" level of desire for public goods, as shown in Figure 8. The widely used metaphor of the boiling frog is illustrated here and in Figure 9; it refers to the ability or inability of people (or any entity) to recognise and react to important adverse changes that occur gradually. ${ }^{4}$ The boiling frog metaphor has been suggested before in relation to surveillance (Marx, 1987, p. 54), and it can also be understood as representing what a former UK Information Commissioner once famously termed "sleepwalking into a surveillance society" (Ford, 2004). The issue of perception may relate to that of timescale; for example, adverse changes taking place gradually over a long period of time may be much harder to perceive than a similar aggregate change taking place over a much shorter time period.

On the other hand, even in a successfully resilient construction, the actors themselves might not be fully aware of their own resilience activities. In other words, there exist perceived shocks and stresses, and unperceived ones, coupled with conscious resilience options and unconscious ones. The possible combinations are manifold. In such situations and also on a societal level, the observer can identify an important moment: the moment of perception (Figure 9).

\footnotetext{
${ }^{4}$ See http://en.wikipedia.org/wiki/Boiling_frog
}

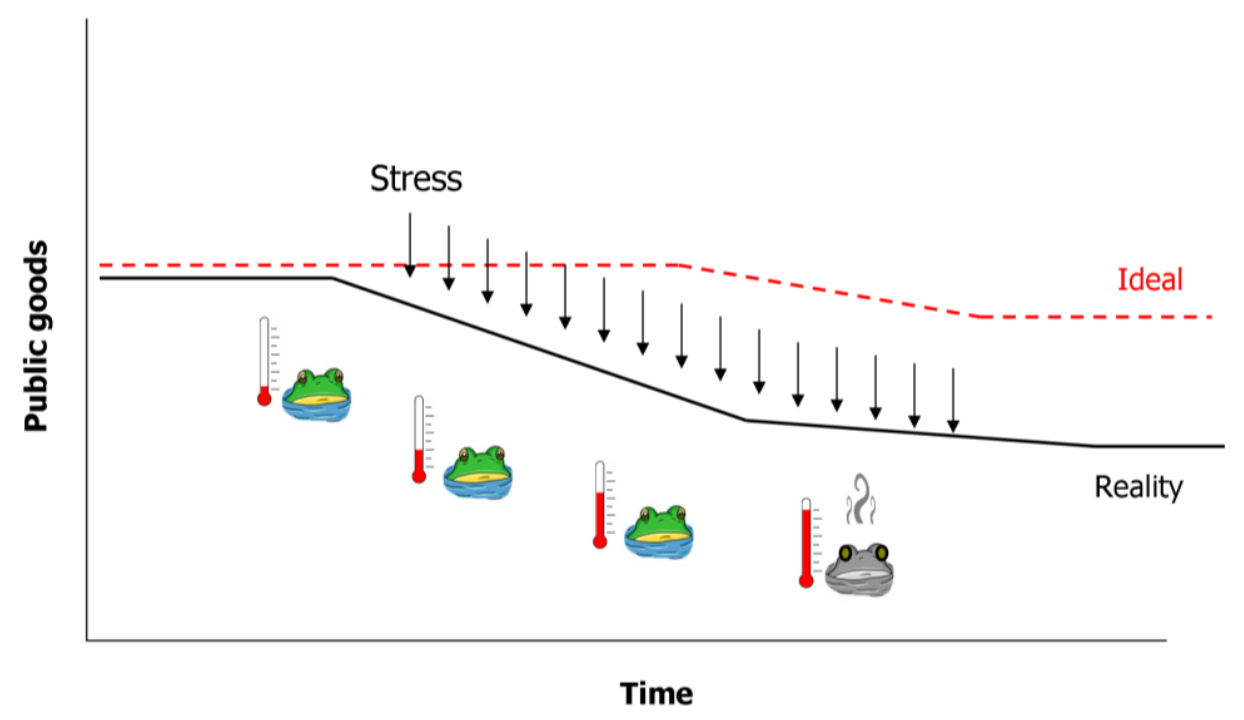

Figure 8. Unperceived stresses and eroding public goods. 


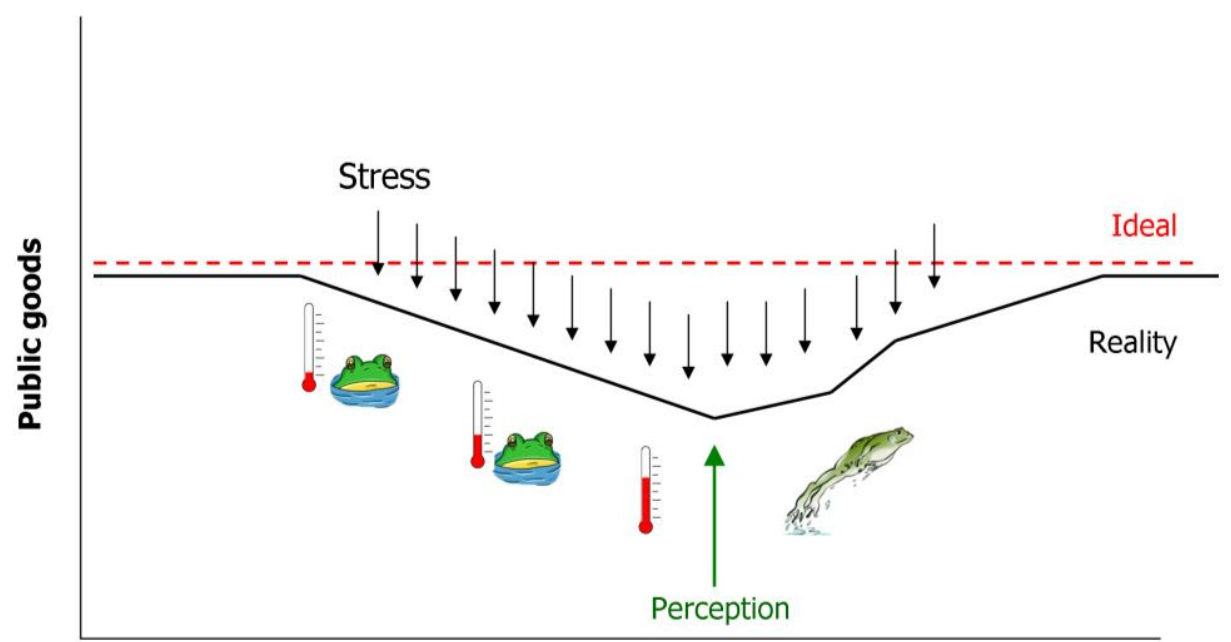

Time

Figure 9. Perceived stresses and chances of resilience.

This diagram depicts a scenario in which the moment of perception prompts action leading to a change of real conditions. However, another scenario (not depicted) could show a case in which it is not possible to change real conditions, so that the moment of perception leads instead only to an increased desire for an "ideal". This can have special importance in the surveillance domain: surveillance stresses, even shocks, are often not perceived by the affected population, not to mention the indirect consequences of such impacts. For example, until the 2013 Snowden revelations of mass surveillance, people in Western societies were only dimly aware of, or even oblivious to, the fact that they had far less communications privacy than they had thought or had reason to expect. The public's valuation of privacy has arguably increased as a consequence of this new awareness. Aradau (2014, p. 79) uses the term "moment of surprise" to describe the moment of perception (which may be experienced immediately in the case of shocks, or belatedly, as here, in the case of incremental stresses). Indeed, she argues that resilience approaches have become popular in policy fields precisely "as a response to the problem of surprising events" (2014, p. 87).

\section{Resilience in the Surveillance Context}

We have argued that much contemporary surveillance, and its effects on public goods, is predicated upon policies and practices aimed at promoting the security of states and societies. In the field of security-which is close to our concerns in thinking about surveillance"resilience" has tended to be used in the sense of "resilience to terrorism/subversion", and the concepts and strategies used are drawn from the lexicon mentioned above. Here we propose to explore how similar resilience mechanisms might be employed to make so- cieties more resilient to the more negative consequences of the state and corporate surveillance that is undertaken in the name of security. However, in doing so, it becomes apparent that certain assumptions of the existing resilience models/paradigm must be called into question. Developing a resilience framework to incorporate different assumptions indicates that various outcomes are possible. We conclude that not only does this suggest that the use of a resilience strategy in opposing greater surveillance should be adopted with only limited optimism, but that our analysis highlights the limits of such resilience in general, including in relation to improving security.

We now take this third step in the modelling of resilience, narrowing down from the general and abstract to consider specifically resilience to surveillance itself as the source of stress. The original Conway et al. (2010) model suggests a way of conceptualising different strategies to oppose or resist surveillance, namely along the broadly temporal sequence of anticipate, survey, prevent, tolerate, recover, restore and learn. Rather than simply reactively opposing insidious surveillance programmes when they are initially proposed or revealed, a "resilience"-based approach suggests that, additionally, it would be beneficial in advance to prepare a raft both of preventive measures and restorative contingency measures.

From this perspective, specific measures that could be deployed to oppose surveillance can be seen as potentially involving a number of these strategy qualities. For example, the establishment of constitutional or human rights legal protections are in part anticipatory (because they anticipate future governmental attempts at their encroachment); in part preventive (because a constitutional court might rely on such provisions to strike down a proposed new law as unconstitutional); restorative (because higher constitutional courts may 
be acting sometime after a law was originally introduced); and exemplify learning (because jurisprudence may develop in the light of new technologies, their capabilities and implications for citizens). Similarly, citizens' use of encryption techniques to protect their personal communications may be anticipatory (of unknown future attempts at their interception); preventive (preventing immediate disclosure); restorative (introduced specifically to reinstate effective privacy in the light of recognition of its former weakness); or demonstrate learning (the adoption of even stronger cryptographic systems in the light of revealed weaknesses).

The second respect in which this analysis of resilience potentially informs overall strategies for curtailing surveillance is that the area of surveillance itself prompts us to question many of the assumptions underpinning conventional models of resilience. As a result, our analysis suggests that considerable caution is warranted and that resilience strategies are no panacea. Snowden's revelation of mass Internet surveillance programmes may present as a sudden major societal shock, and be met with resistance or recovery processes of certain kinds that could reasonably be characterised as "resilience". However, this surveillance, deployed gradually and stealthily for many years, went unnoticed and unchallenged (see Figures 8 and 9). Moreover, it remains to be seen whether future governmental mass surveillance programmes will successfully be constrained, given the temptations they may offer, the vested interests in the intelligence community, and international as well as national considerations. Furthermore, we may also speculate that societal valuing of privacy may have become eroded rather than reinforced as a result of the recent disclosures, leading to a resigned acceptance of the impossibility of truly pri- vate personal communications in the digital age.

The diagrams below illustrate, in a unified structure, both security- and surveillance-related stresses, as well as resilience responses towards them. Figure 10 shows the adverse impacts and the resilience responses reflecting the traditional trade-off model between security and privacy: the trajectories of these two public goods are shown within the diagram. This model presupposes that, with regard to their privacy implications, citizens evaluate the introduction and use of security/surveillance technologies in terms of a trade-off; in other words, they regard such situations as a zerosum game: more security equals less privacy and viceversa. This popular hypothesis implies that, under threats to security, security will trump privacy. The diagram also shows the presupposition that surveillance measures are natural consequences of terror and other threats to security, thereby representing stresses of their own, too, in a chain-like pattern.

Recent research challenges the universal validity of this trade-off model and criticises its use in legitimising the introduction of privacy-invasive security technologies. Empirical studies investigating people's perception and attitudes in this area indicate that people regard security and privacy as two separate public goods, and that they want both simultaneously. ${ }^{5}$ In such a model both remain unchanged during stresses and shocks of both types; in an ideal situation, as a result of resilience responses towards both types of stress, the real situation remains unchanged as well (Figure 11).

${ }^{5}$ Most significantly the PRISMS project, (The PRIvacy and Security MirrorS): "Towards a European Framework for Integrated Decision-Making", Project No. 285399, $7^{\text {th }}$ Framework Programme of the European Commission.

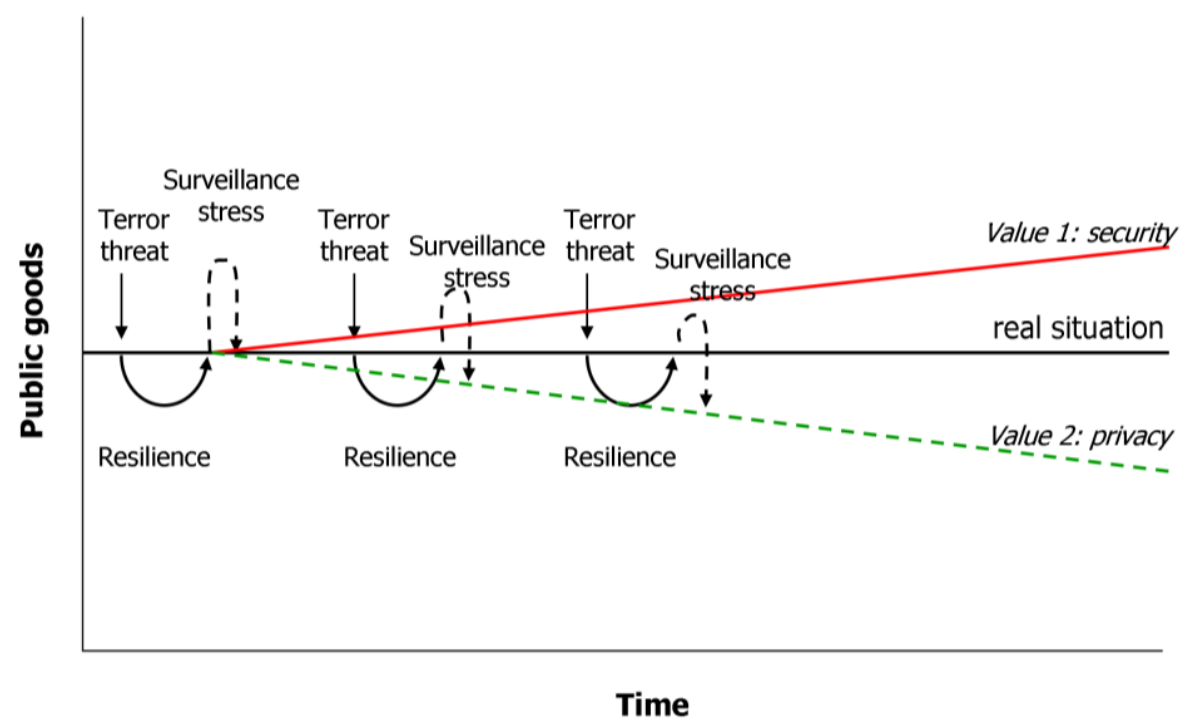

Figure 10. Terror threats and surveillance stresses in a security/privacy trade-off model. 


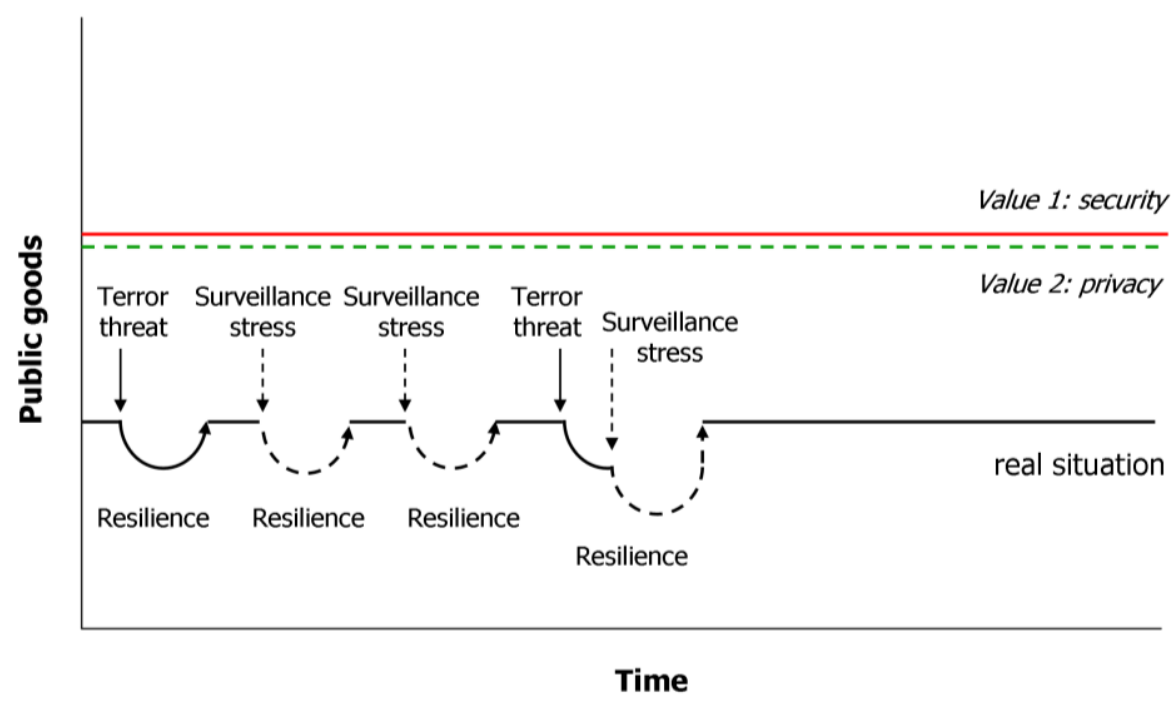

Figure 11. Terror threats and surveillance stresses in a separate public goods model (ideal situation).

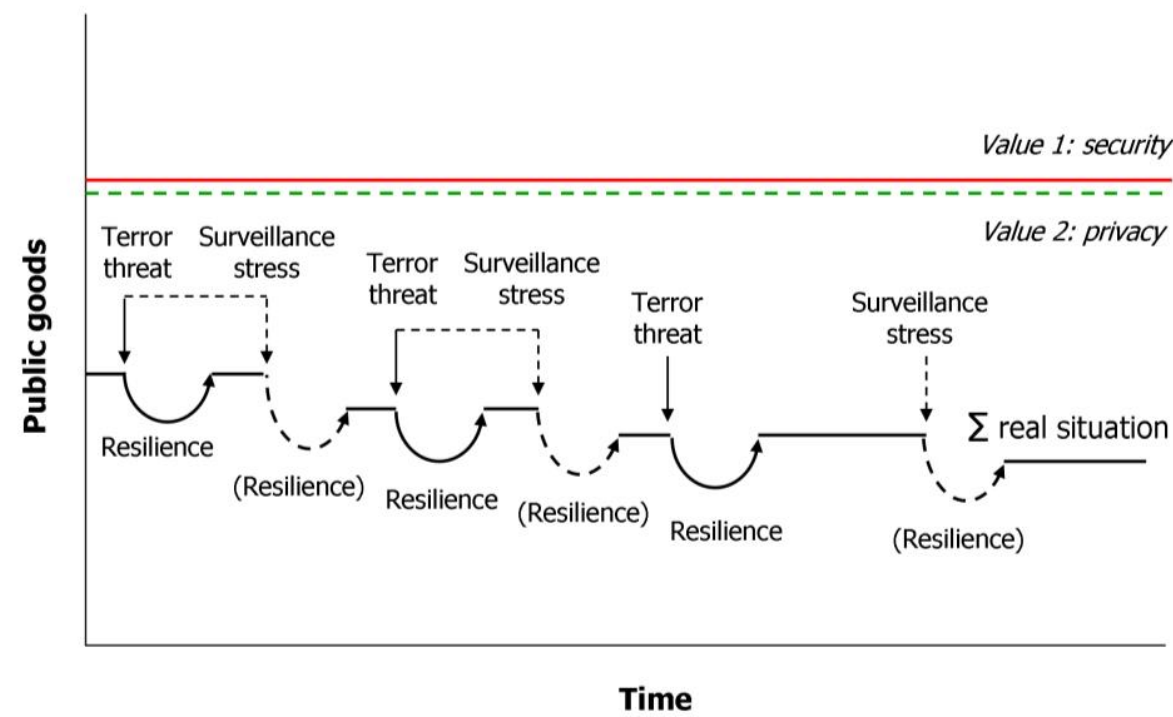

Figure 12. Terror threats and surveillance stresses in a separate public goods model (observed situation).

However, even if the society or a substructure is resilient towards security threats and shocks and bounces back to the original state of normalcy, this may not be reflected in the context of surveillance: the negative consequences of surveillance-such as increased social sorting, detrimental effects upon the social capital of interpersonal trust and social solidarity, or the erosion of privacy-result in worsening the summation $(\Sigma)$ of the two components of the real situation, as illustrated in Figure 12. This figure usefully helps visualise that the public goods of security and privacy may indeed continue to be held in high esteem, but that this may nonetheless mask the gradual erosion in the real situation of citizens" enjoyment of these public goods.

\section{Conclusion}

There are a number of benefits of creating a general framework for the modelling of resilience, both in order to understand better the capabilities and limits of resilience approaches in general, and in order to model the threats posed by surveillance in particular. First, it helps both to organise existing knowledge, and to indicate gaps; second, it shows the relationship between, and ways of integrating, different resilience instruments; and third, the model can be applied at many different levels, from the local to the global. Such models consist of concepts that together describe, abstractly and schematically, what it means to be resilient in a host of specific contexts and applications. We have focused upon one context: surveillance for the purpose of (national) security.

It could be argued that elements of a strategy of resilience in the face of threats posed by surveillance are already to be found. Civil liberties and Internet privacy groups regularly campaign against government pro- 
posals for new legislation introducing surveillance measures, which we could understand as "resistance" activities. Many countries afford protections to their citizens in respect of fundamental rights, whether by means of constitutional provisions, international treaty obligations, privacy laws and other instruments (Bennett \& Raab, 2006), which could be understood as, in large part, an anticipatory or preventive resilience strategy against possible future governmental attempts at their erosion.

Our argument here is that, in two respects, attending to the notion of resilience is useful in understanding the prospect of societal "pushback" in the face of greater surveillance. The first is that it potentially offers surveillance activists a framework for developing a wider range of measures and tactics for opposing surveillance. However, second, and more directly the focus of the present article, is that while the notion of resilience brings with it a consideration of anticipatory, immediate and future responses, it encompasses an unspecified and hence ambiguous time-frame of analysis, which could various refer to the short term, medium term, and even perhaps approach the longue durée. This is why the horizontal axis of the diagrams, and the vertical axis for that matter, are not calibrated to show intervals or magnitudes. Beyond the weeks, months, or few years in which we are accustomed to reckon the span of events, the unfolding of resilience-including the habits, outlooks, myths and stories, and institutional changes - that takes place in societies and cultures may follow a trajectory that encompasses many generations: historical time, not journalistic time.

The terminology of resilience has tended to be associated with strategies to enhance security, including the possible deployment of further state-surveillance measures. As a consequence, "resilience" as a concept has tended to be viewed as associated with securitisation processes evaluated as "good". However, this article has argued that, in the abstract at least, resilience can be regarded as neutral, and that its evaluation is a consequence of its application. Moreover, since "resilience" is an umbrella concept gathering together a range of measures designed to thwart an undesirable challenge or to remedy its effects, it offers a way of unifying such individual measures into a coherent strategy. Since it both suggests a concrete framework for developing policy and describes a desired on-going quality of a successful scenario, a repurposed application of the concept suggests ways in which democratic societies might become more resilient to the threats posed by surveillance itself.

This perspective is particularly useful in helping to understand different societal responses in the face of attempts at surveillance expansionism over time. This is because it enables us to model and explore different scenarios and outcomes-still, of course, to be elaborated and then tested empirically-including those in which surveillance measures expand to the detriment of public goods, and hence in which resilience to surveillance may be said to have failed. As such, and unlike many previous models of resilience, the models presented here do not assume resilience strategies always to prove successful. The diagrammatic representation of resilience prepared by Conway et al. (2010) represents a significant advance over the "optimistic" versions of resilience policy often informing resilience strategies, insofar as it acknowledges the possibility of negative outcomes (a "failure" of a system to prove itself "resilient"). However, the diagram is ambiguous as to whether it represents a normative goal or a description of a state of affairs. By separating these two qualities, we have been able to offer different scenarios involving interactions (but also divergences) between the two. As well as offering a cautionary note as to the likelihood of success of resilience-based strategies in opposing surveillance, an implication of the analysis presented here is that governments and authorities should be similarly circumspect regarding the efficacy of counter-terrorist and other state security resilience strategies, including the imposition of surveillance, since the same limitations apply.

Crucially, this article has contended that whilst surveillance strategies may (ironically) be deployed by societies in the name of greater "security", surveillance measures may have significant long-term detrimental consequences for constitutive public goods such as privacy, and hence be detrimental to society more generally. Whereas it has long been noted within surveillance studies that surveillance may produce a "chilling effect" on social and political debate, our analysis has identified more long-term, but no less insidious, consequences of increased surveillance of citizens, and this has to be taken into consideration in the fields of security studies and resilience studies alike.

\section{Acknowledgments}

Some of our thinking about surveillance and resilience took shape within the European Commission's FP7funded project on Increasing Resilience in Surveillance Societies (IRISS), EC Grant Agreement No. 285593, 2012-2015. We are grateful for comments by IRISS colleagues in conferences and lectures organised in 2014 by the Surveillance Studies Network, by King's College London, and by the Eotvos Lorand University (ELTE) Faculty of Law.

\section{Conflict of Interests}

The authors declare no conflict of interests. 


\section{References}

Aradau, C. (2014). The promise of security: resilience, surprise and epistemic politics. Resilience: International Policies, Practices and Discourses, 2(2), 73-87.

Ban, K.-m. (2009). Resilience and solidarity: Our best response to crisis. Address to the 62nd World Health Assembly, 19 May 2009. Retrieved from http://www.who.int/mediacentre/events/2009/wha 62/secretary_general_speech_20090519/en

Béné, C., Godfrey Wood, R., Newsham, A., \& Davies, M. (2012). Resilience: New utopia or new tyranny? Reflection about the potentials and limits of the concept of resilience in relation to vulnerability reduction programmes (IDS Working Paper 405, September 2012). Brighton: IDS. Retrieved from http://www.ids.ac.uk/ publication/resilience-new-utopia-or-new-tyranny

Bennett, C. J. (2008). The privacy advocates: Resisting the spread of surveillance. Cambridge, MA: MIT Press.

Bennett, C. J., \& Raab, C. D. (2006). The governance of privacy: Policy instruments in global perspective. Cambridge, MA: MIT Press.

Bourbeau, P. (2013). Resiliencism: Premises and promises in securitisation research. Resilience: International Policies, Practices and Discourses, 1(1), 3-17.

Bourbeau, P. (2015a). Resiliencism and security studies: Initiating a dialogue. In T. Balzacq (Ed.), Contesting security (pp. 173-188). Abingdon: Routledge.

Bourbeau, P. (2015b). Resilience and international politics: Premises, debates, agenda. International Studies Review, forthcoming.

Braybrooke, D, \& Lindblom, C. E. (1963). A strategy of decision: Policy evaluation as a social process. New York, NY: Free Press.

Čas, J., Strauss, S, Amicelle, A., Ball, K., Hallinan, D., Friedewald, M., \& Szekely, I. (2015). Social and economic costs of surveillance. In D. Wright \& R. Kreissl (Eds.), Surveillance in Europe (pp. 211-258). London: Routledge.

Chandler, D. (2012). Resilience and human security: The post-interventionist paradigm. Security Dialogue, 43(3), 213-229.

Chandler, D. (2013a). Editorial. Resilience: International Policies, Practices and Discourses, 1(1), 1.

Chandler, D. (2013b). Pre-emptive strike: A response to "resisting resilience". Radical Philosophy, 179, 58-59.

Chandler, D. (2015). Resilience and the "everyday": Beyond the paradox of "liberal peace". Review of International Studies, 41(1), 27-48.

Cho, A., Willis, S., \& Stewart-Weeks, M. (2011). The resilient society: innovation, productivity, and the art and practice of connectedness. San José, CA: Cisco Internet Business Solutions Group (IBSG). Retrieved from http://www.cisco.com/web/about/ac79/docs/ps/Th e-Resilient-Society_IBSG.pdf

Clarke, R. (2013). Notes of 5 February 2013 for the Advi- sory Board of the Increasing Resilience in Surveillance Societies (IRISS) project. Retrieved from http://www.rogerclarke.com/DV/IRISSR.html

Conway, G., Waage, J. K., \& Delaney, S. (2010). Science and innovation for development. London: UK Collaborative on Development Science.

Demerath, N. J. III, \& Peterson, R. A. (Eds.). (1967). System, change and conflict: A reader on contemporary sociological theory and the debate over functionalism. New York, NY: Free Press.

Deutsch, K. W. (1963). The nerves of government: Models of political communication and control. New York, NY: Free Press of Glencoe.

Durkheim, E. (1984 [1893]). The division of labor in society. New York, NY: Free Press/Macmillan.

Easton, D. (1965). A systems analysis of political life. New York, NY: John Wiley \& Sons.

Emery, F. E. (Ed.). (1969). Systems thinking: Selected readings. Harmondsworth: Penguin Books.

European Commission. (2012). Communication from the Commission to the European Parliament and the Council-The EU approach to resilience: Learning from food security crises (COM(2012) 586 Final, Brussels, 3.10.2012). Brussels: European Commission.

Evans, B., \& Reid, J. (2013). Dangerously exposed: The life and death of the resilient subject. Resilience: International Policies, Practices and Discourses, 1(2), 83-98.

Feibleman, J., \& Friend, J. W. (1945). The structure and function of organization. The Philosophical Review, 54(1), 19-44.

Fernandez, L. A., \& Huey, L. (2009). Is resistance futile? Thoughts on resisting surveillance. Surveillance and Society, 6(3), 199-202.

Folke, C. (2006). Resilience: The emergence of a perspective for social-ecological systems analysis. Global Environmental Change, 16, 253-267.

Ford, R. (2004, August 16). Beware rise of Big Brother state, warns data watchdog, The Times.

Greenwald, G. (2014). No place to hide. London: Hamish Hamilton.

Hall, P., \& Lamont, M. (Eds.). (2013a). Social resilience in the neoliberal era. Cambridge: Cambridge University Press.

Hall, P., \& Lamont, M. (2013b). Introduction. In P. Hall \& M. Lamont (Eds.), Social resilience in the neoliberal era. Cambridge: Cambridge University Press.

Hamel, G., \& Välikangas, L. (2003). The quest for resilience. Harvard Business Review, 1 September, Watertown, MA: Harvard Business Publishing. Retrieved from https://hbr.org/2003/09/the-quest-for-resilience

Holling, C. S. (1998). Two cultures of ecology. Conservation Ecology, 2(2), article 4. Retrieved from http://www.consecol.org/vol2/iss2/art4

Hood, C. C. (1983). The Tools of government. London: Macmillan.

International Strategy for Disaster Reduction (ISDR). 
(2004). Living with risk: A global review of disaster reduction initiatives (Volume I). New York and Geneva: United Nations. Retrieved from http://www. unisdr.org/files/657_Iwr1.pdf

Introna, L., \& Gibbons, A. (2009). Networks and resistance: Investigating online advocacy networks as a modality for resisting state surveillance. Surveillance and Society, 6(3), 233-258.

Loader, I., \& Walker, N. (2007). Civilizing security. Cambridge: Cambridge University Press.

Longstaff, P. H. (2005). Security, resilience, and communication in unpredictable environments such as terrorism, natural disasters and complex technology. Cambridge, MA: Center for Information Policy Research, Harvard University. Retrieved from http://pirp.harvard.edu/pubs_pdf/longsta/ longstap05-3.pdf

Los, M. (2002). Post-communist fear of crime and the commercialization of security. Theoretical Criminology, 6(2), 165-188.

Luthar, S. S., Cicchetti, D., \& Becker, B. (2000). The construct of resilience: A critical evaluation and guidelines for future work. Child Development, 71(3), 543562.

Lyon, D. (Ed.). (2003a). Surveillance as social sorting: Privacy, risk and digital discrimination. London: Routledge.

Lyon, D. (2003b). Surveillance after September 1. Cambridge: Polity Press.

Martin, A., Brakel, R. van, \& Bernhard, D. (2009). Understanding resistance to digital surveillance: Towards a multidisciplinary, multi-actor framework. Surveillance and Society, 6(3), 213-232.

Marx, G. T. (1987). Restoring realism and logic to the covert facilitation debate. Journal of Social Issues, 43(3), 43-55.

Marx, G. T. (2015). Security and surveillance contests: Resistance and counter-resistance. In T. Balzacq (Ed.), Contesting security (pp. 15-28). Abingdon: Routledge.

Neocleous, M. (2013a). Resisting resilience. Radical Philosophy, 178, 2-7.

Neocleous, M. (2013b). A reply. Radical Philosophy, 179, 59.

Nissenbaum, H. (2010). Privacy in context: Technology, policy, and the integrity of social life. Stanford, CA: Stanford University Press.

Parsons, T. (1951). The social system. New York, NY: Free Press of Glencoe.

Putnam, R. D. (2000). Bowling alone: the collapse and revival of American community. New York, NY: Simon $\&$ Schuster.

Raab, C. D. (2012). Privacy, social values and the public interest. In A. Busch \& J. Hofmann (Eds.), Politik und die Regulierung von Information [Politics and the Regulation of Information], Politische Vierteljahresschrift Sonderheft 46 (pp. 129-151). Baden-
Baden: Nomos Verlagsgesellschaft.

Raab, C. D. (2014). Privacy as a security value. In D. W. Schartum, L. Bygrave, \& A. G. B. Bekken (Eds.), Jon Bing: En Hyllest/A Tribute (pp. 39-58). Oslo: Gyldendal.

Raab, C., Hallinan, D., Amicelle, A., Galdon Clavell, G., Galetta, A., De Hert, P., \& Jones, R. (2015). Effects of surveillance on civil liberties and fundamental rights in Europe. In D. Wright \& R. Kreissl (Eds.), Surveillance in Europe (pp. 259-318). London: Routledge.

Sampson, R. J. (2008). Collective efficacy theory: Lessons learned and directions for future inquiry. In F. Cullen, J. Wright, \& K. Blevins (Eds.), Taking stock: The status of criminological theory (pp. 149-167). New Brunswick: Transaction Publishers.

Sanchez, A. (2009). Facebook feeding frenzy: Resistancethrough-distance and resistance-through-persistence in the societied network. Surveillance and Society, 6(3), 275-293.

Slater, T. (2014, January 28). The resilience of neoliberal urbanism, Open Security. Retrieved from http://www.opendemocracy.net/opensecurity/tomslater/resilience-of-neoliberal-urbanism

Solove, D. (2008). Understanding privacy. Cambridge, MA: Harvard University Press.

Szekely, I. (2008). Hungary. In J. Rule \& G. Greenleaf (Eds.), Global privacy protection: The first generation (pp. 174-206). Cheltenham: Edward Elgar.

Taleb, N. N. (2013). Antifragile. London: Penguin (Allen Lane).

The Montpellier Panel (2012). Growth with resilience: Opportunities in African agriculture. London: Agriculture for Impact. Retrieved from https://workspace. imperial.ac.uk/africanagriculturaldevelopment/Pu blic/Montpellier\%20Panel\%20Report\%202012.pdf

UK Cabinet Office. (2011a). The UK cyber security strategy protecting and promoting the $U K$ in a digital world. London: Cabinet Office. Retrieved from https://www.gov.uk/government/uploads/system/u ploads/attachment_data/file/60961/uk-cybersecurity-strategy-final.pdf

UK Cabinet Office. (2011b). Strategic national framework on community resilience. London: UK Cabinet Office. Retrieved from https://www.gov.uk/ government/uploads/system/uploads/attachment _data/file/60922/Strategic-National-Framework-onCommunity-Resilience_0.pdf

UK Cabinet Office. (2013). Resilience in society: Infrastructure, communities and businesses-How networks and individuals can support the country's emergency planning, response and recovery, and keep systems and services running. London: UK Cabinet Office. Retrieved from https://www.gov.uk/ resilience-in-society-infrastructure-communitiesand-businesses

UK Home Office. (2011). CONTEST: The United Kingdom's strategy for countering terrorism ( $\mathrm{Cm} \mathrm{8123).}$ 
London: The Stationery Office Limited.

UN Commission on Narcotic Drugs/Commission on Crime Prevention and Criminal Justice. (2010). Drug control, crime prevention and criminal justice: A Human Rights perspective (Note by the Executive Director), E/CN.7/2010/CRP.6-E/CN.15/2010/CRP.1, 3 March 2010. Retrieved from http://www.unodc. org/documents/commissions/CND-Uploads/CND-53 RelatedFiles/ECN72010_CRP6eV1051605.pdf

UN Security Council, Counter-Terrorism Committee (CTED). (2013). Special Event, 24 May 2013. Retrieved from http://www.un.org/en/sc/ctc/news/ 2013-05-30_Special_Event_New_Tech.html and http://www.un.org/en/sc/ctc/docs/2013/2013-0524_opening_stmt_chair.pdf

UN System Task Team on the Post-2015 UN Development Agenda. (2012). Disaster risk and resilienceThematic Think Piece, May 2012. Retrieved from http://www.un.org/en/development/desa/policy/un taskteam_undf/thinkpieces/3_disaster_risk_resilienc e.pdf

United Nations Secretary-General's High-level Panel on Global Sustainability. (2012). Resilient people, resilient planet: A future worth choosing. New York, NY: United Nations. Retrieved from https://en.unesco. org/system/files/GSP_Report_web_final.pdf

Walker, B., \& Salt, D. (2006). Resilience thinking: Sustaining ecosystems and people in a changing world.
Washington, DC: Island Press.

Walklate, S., \& Mythen, G. (2015). Contradictions of terrorism: Security, risk and resilience. Abingdon: Routledge.

Wells, H., \& Wills, D. (2009). Individualism and identity: Resistance to speed cameras in the UK. Surveillance and Society, 6(3), 259-274.

White, I., \& O'Hare, P. (2014). From rhetoric to reality: Which resilience, why resilience, and whose resilience in spatial planning? Environment and Planning C: Government and Policy, 32(5), 934-950.

Wiener, N. (1954). The human use of human beings: $\mathrm{Cy}$ bernetics and society. Garden City, NY: Doubleday Anchor Books.

Wright, D., \& Kreissl, R. (2015). Resilience in Europe's surveillance society. In D. Wright \& R. Kreissl (Eds.), Surveillance in Europe (pp. 319-359). London: Routledge.

Wright, D., \& Raab, C. (2014). Privacy principles, risks and harms. International Review of Law, Computers \& Technology, 28(3), 277-298.

Yusuf, S. (2012). The resilience of the human rights norm in an era of counter-terrorism (UNISCI Discussion papers no. 28, January 2012). Madrid: Research Unit on International Security and Cooperation (UNISCI). Retrieved from http://revistas.ucm.es/index.php/UNIS/ article/viewFile/38472/37211

\section{About the Authors}
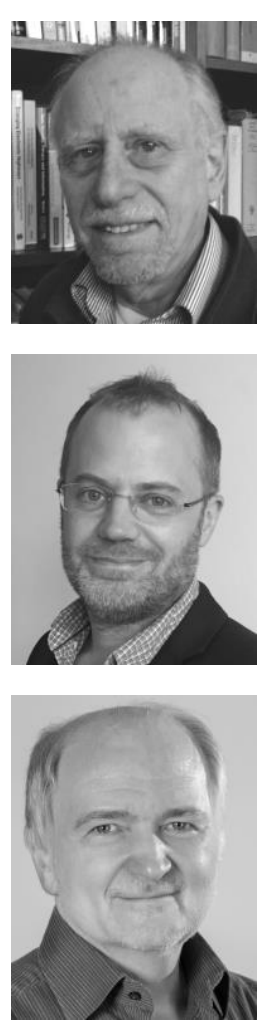

\section{Charles Raab}

Charles Raab is Professorial Fellow, University of Edinburgh, and a Director of the Centre for Research into Information, Surveillance and Privacy (CRISP). His research concerns privacy, surveillance, security and democracy. He has given evidence to UK parliamentary committees and was Specialist Adviser to the House of Lords Constitution Committee for the inquiry, Surveillance: Citizens and the State, HL Paper 18, Session 2008-09. He is a Fellow of the Academy of Social Sciences and a Fellow of the Royal Society of Arts.

\section{Dr. Richard Jones}

Richard Jones is Lecturer in Criminology and Mid-Career Research Development Fellow at the School of Law, University of Edinburgh, UK. He has a PhD in Criminology from the Institute of Criminology, University of Cambridge, and has been a Visiting Academic at the Centre for Criminology, University of Oxford. His research focuses on the use of new technologies in criminal justice and crime control. He was a member of the EU'S FP7 IRISS Project on surveillance, resilience and democracy, and was an External Expert on Cybercrime for the FP7 FIDUCIA project.

\section{Dr. Ivan Szekely}

Ivan Szekely, social informatist, is an internationally known expert in the multidisciplinary fields of data protection and freedom of information. A long-time independent researcher, consultant and university lecturer, as well as former chief counsellor of the Hungarian Parliamentary Commissioner for Data Protection and Freedom of Information, Szekely is at present Senior Research Fellow of the Open Society Archives at Central European University, associate professor at the Budapest University of Technology and Economics, and advisory board member of the Eotvos Karoly Policy Institute. 